\title{
Developing Material Requirements for Automotive Brake Disc
}

\author{
Samuel A Awe* \\ $R \& D$ Department, Automotive Components Floby AB, Sweden
}

*Corresponding author: Samuel A Awe, R\&D Department, Automotive Components

Floby AB, Aspenäsgatan 2, SE-521 51 Floby, Sweden.

Received Date: November 12, 2019

Published Date: November 15, 2019

\begin{abstract}
As electric vehicles are becoming more popular in society and several regulations concerning vehicle safety and performance as well as particulate matter emissions reduction are progressively becoming stringent, the author opines that these determinants would shape future automotive brake discs development. This mini-review highlights some of the essential parameters that would contribute to the next brake disc design and development and discusses how these factors will govern the choice of brake disc material in the coming years.
\end{abstract}

Keywords: Automotive vehicle; Brake system; Brake discs; Particle emissions; Lightweight; Regulations; Corrosion; Electric cars

\section{Introduction}

The automotive vehicle has transformed and will continue to change human's mobility in the future. To ensure the safety of lives and properties, the braking system, which is a crucial component of an automobile plays an essential role in the safe drive of a car. The primary function of automotive friction brakes is to generate a braking torque that decelerates the vehicle's wheel and therefore brings it to a stop. In a broad view, the fundamental tasks of car braking systems include - i) to reduce the speed of the vehicle, ii) to bring the car to a halt, iii) to prevent unwanted acceleration during downhill driving, and iv) to keep the vehicle stationary when it is stopped [1]. However, friction brakes work on the principle that the friction pads are pressed against a rotating disc, and thereby produce frictional forces that slow down the rotating disc, and consequently reduces the speed of the car or completely stops it. During the braking process, the brake pads press against the brake disc, and frictional heat is generated, which is absorbed and dissipated by the brakes and its components. There are two types of brakes - the disc brake and the drum brake. Disc brake can be used on all the four wheels of a car or used in combination with drum brakes on the rear and disc brakes on the front wheels.

For automobiles, the most commonly used brake disc material is grey castiron (GCI), because it possesses excellent friction properties, has low cost, retains strength at elevated temperature, has relative ease of manufacture and is thermally stable. Unfortunately, the weak corrosion resistance, heavyweight and weak wear resistance are some of the drawbacks of grey cast iron as brake disc material. Nonetheless, the functional requirements for automotive brake discs nowadays are becoming stricter, prompted by the stringent regulations to reduce vehicle emissions, the emergence of electric vehicles, demands to improve vehicle safety and performance, and the desire to enhance the driving experience of cars. In all these challenging scenarios, materials play a crucial function, which is an indication that their role in the design and development of a vehicle is vital. In the automotive industry, for example, they are employed in every facet of the vehicle's engineering and construction. The automotive brake discs are manufactured from materials. The disc materials must possess specific requirements that allow the brake discs to function safely and effectively under the harsh conditions in which they operate. Based on their functions, brake disc materials should have high strength even at elevated temperatures, high thermal conductivity, excellent abrasion resistance, good creep resistance, high stiffness and superior corrosion resistance [2]. However, the current and future trends in the automotive industry are tending towards lightweight solutions [3], particulate matter (PM) and $\mathrm{CO}_{2}$ emission reductions [4,5], improved corrosion resistant, cost reduction, and better performance and enjoyable driving experience. As a result of vehicles' electrification, stringent government regulations regarding vehicle emissions and increasing demand for an enjoyable driving experience, several functional 
requirements are being placed on the automotive brake disc material, which is envisaged to continue in the future brake disc development. The overview of some of the trending in brake disc material requirements is briefly discussed.

\section{Current and Future Demands on Automotive Brake Discs}

For a vehicle brake discs to cope with the functional demands on them, the existing brake disc materials should be modified, or new materials possessing the needed properties are developed. This section highlights some of the trending factors that impose more functional requirements on brake disc materials.

\section{Vehicle emissions}

Emissions generated from automobiles cannot be ignored because they are a potential environmental pollutant and lead to the human health hazard. It was reported that road transport emissions account for a significant share of premature adult deaths in the European Region, which was attributed to air pollution occurring each year [6]. Due to the dangerous impact of vehicle emissions, several legislations and policies have been promulgated by several concerned government authorities globally to curtail these emissions. Road transport emissions include both exhaust (tailpipe) and non-exhaust (tire wear, road abrasion and brake wear) emissions. Figure 1 shows the trend of both exhaust and nonexhaust emissions within the EU15 plus Norway and Switzerland from the year 2000 to 2014. It is noted that the exhaust emissions had reduced drastically. From 2012, non-exhaust emissions began to dominate the emissions within these countries, primarily due to the strategies put in place by the European Commission to limit the exhaust emissions and partly due to the advent of electric vehicles.

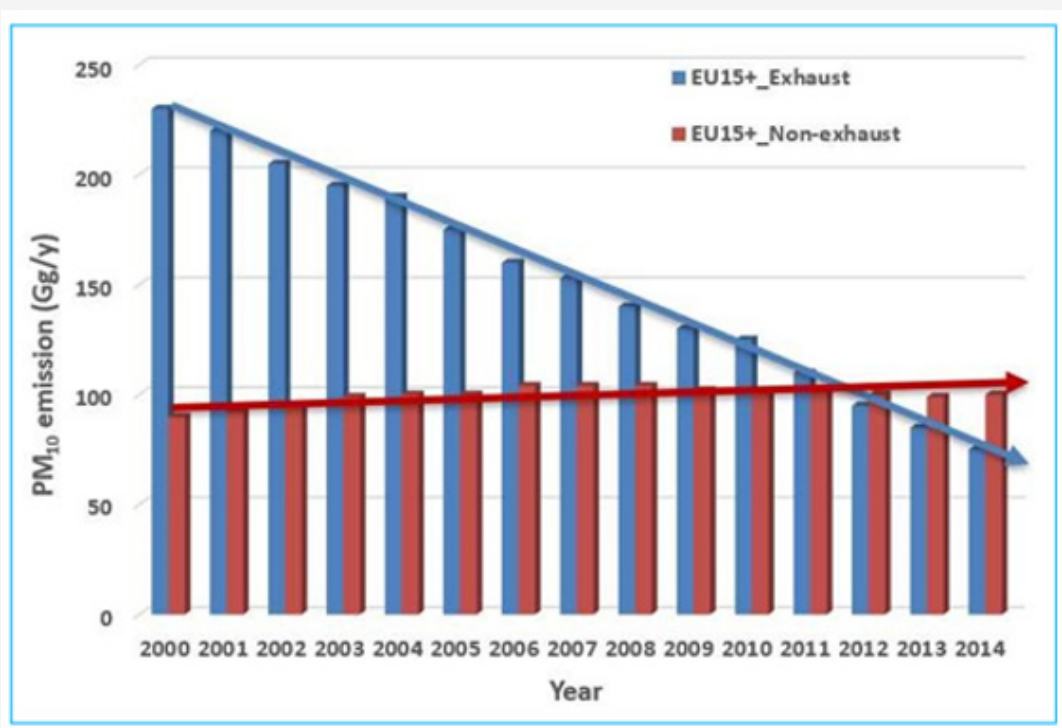

Figure 1: $\mathrm{PM}_{10}$ emission from road transport exhaust and non-exhaust 2000-2014 for EU15, Norway and Switzerland, adapted from reference [5].

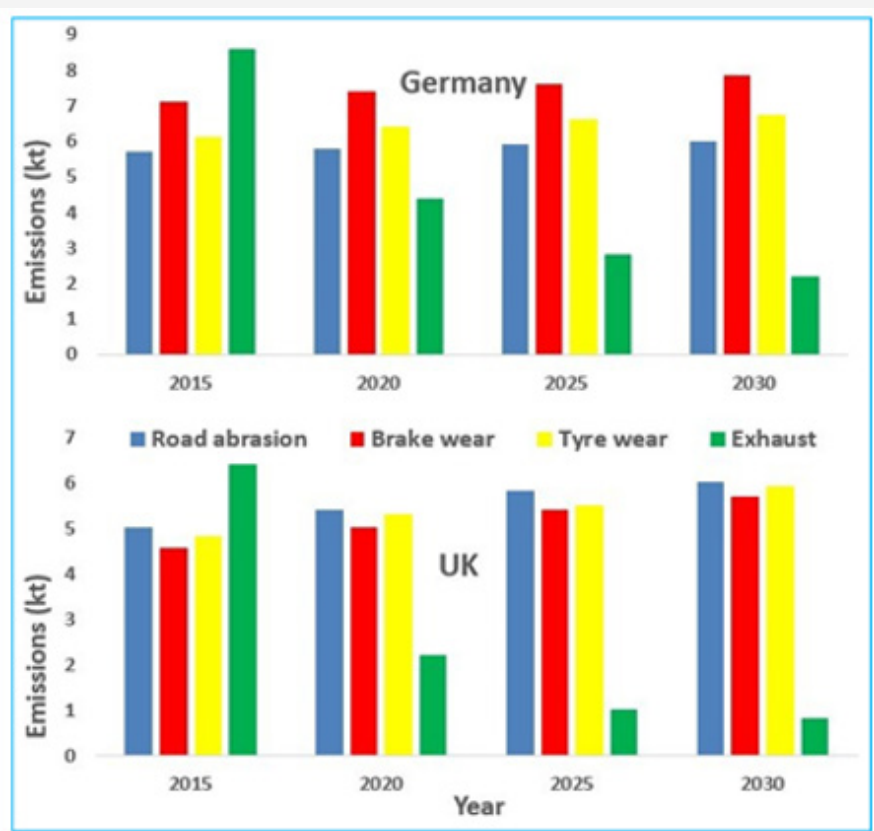

Figure 2: $\mathrm{PM}_{10}$ emissions from road transport sources according to the UK and German Inventories, adapted from reference [10]. 
A similar trend is observed in Figure 2, which compares the road transport emissions generated in Germany and the United Kingdom. The figure predicts that from 2020, non-exhaust emissions will dominate road transport emissions. Brake wear is one of the most significant contributors to particulate matter emissions to the atmosphere [7]. The contributions from brake wear will become prominent in the coming years as electric cars become more dominant of the transportation system. Electric vehicles have the benefit of having no tailpipe emissions but still have tires and brakes [8]. The prevalence of non-exhaust discharge will attract new legislations and policies from the government in the future. As a consequence of the impending regulations to control non-exhaust emissions, the automakers will be forced to seek for alternative brake disc and pad materials or modify the existing ones using surface treatment technology [9] in order to meet these stringent regulations, and thus, will drive new markets for brake materials in the coming years.

\section{Lightweighting}

Lightweighting is an important concept that has been and is currently trending in the automotive design. This concept will remain relevant in the future automobile's design and development. The purpose of lightweight in the automotive design is to reduce the total weight of a vehicle, and by so doing fuel economy can be achieved [11], exhaust emissions from cars can also be reduced as well as enhancing the safety and driving performance of the vehicle. Besides, application of lightweight material such as aluminum matrix composite for brake discs will provide increased acceleration, reduced braking distance, reduced noise (groan and squeal), higher wear resistance, and uniform friction [12]. Regenerative braking increases the total weight of an EV by approximately $25-30 \mathrm{~kg}$, which could increase vehicle traction during start-up. By using lighter brake discs, the ramping-up of driving performance of EVs improves by reducing the unspring mass of the brake system. The implication of this is that lightweight disc materials will be sought for by the brake manufacturers to enhance driving performance.

\section{Improved disc corrosion resistance}

Brake failure due to corrosion will become very significant in electric cars in the future since the friction brake system is less frequently used. The problem of rusting occurring on the friction surfaces of the brake discs, as shown in Figure 3, will be prevalent and drastic. GCI is the traditional material commonly used for brake disc application in automobiles. Its adoption, as a disc material, is primarily due to the favorable properties it possessed. Unfortunately, GCI has a little resistance to aqueous corrosion, and this poses a severe problem for brake discs application because they are naturally exposed to water, humidity, and road salt [13]. In the conventional cars, the corrosion product built on the friction surfaces of the GCI disc is regularly cleansed by the brake pads during several brake applications. The problem of rust will be more critical for electric vehicles since friction brakes are seldom used, and this will allow oxide layer build-up on the disc's friction surfaces for an extended period, which will lead to corrosion- induced friction instability [14], and even outright failure of the brake system. The weak corrosion resistance of GCI could lead to an undesirable situation called brake judder, which may become more prominent in the future in the EVs. This will propel the automakers to adapt the traditional GCI brake discs through surface treatment technology in order to curb the corrosion issue. Brake pad manufacturers might alter the formulation of their pads to include more abrasive materials that could easily remove the corrosion product from the friction surfaces of the rotor. The challenge could also speed up further developmental research on aluminum matrix composite material as an alternative brake disc material.

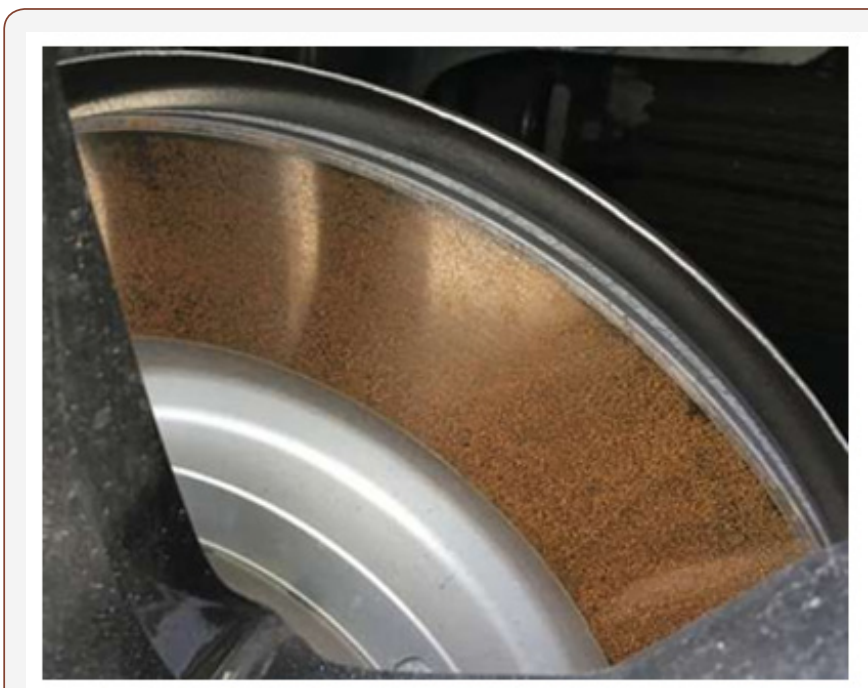

Figure 3: Corroded friction surface of an electric vehicle's brake disc.

\section{Disc brake noise reduction}

Disc brake noise is currently one of the significant challenges confronting the automobile manufacturers throughout the world. It is known that brake noise is not a safety issue and has little effect on braking performance, but its occurrence gives customers the impression of underlying quality problems of the vehicle. Also, the noise emanated from the brake system is perceived by the customers as an indicator of malfunctioning condition and thus lose confidence in the quality of the vehicles [15]. Unfortunately, this issue has resulted in several recalls of cars by the automakers and has attracted expensive warranty claims from both brakes and vehicle manufacturers. The problem of brake noise will be of significant concern in the coming years when EVs have entirely dominated the automotive world. This is because EVs work very quietly unlike the internal combustion engine cars, where the engine noise is somehow damping the brake squeal noise, which implies that the squealing noise from the braking system will be well-pronounced in EVs. To conform to the progressively stringent noise constraints, the brake manufacturers must redesign the existing one or seek for a new material that meets the requirements.

Maximum operating temperature - In conventional cars, the brake discs are subjected to a high level of thermal load during brake applications, which results in a sudden increase in the heat of 
the system and a temperature as high as $700^{\circ} \mathrm{C}$ could be reached on the friction surfaces of the disc. The entrance of EVs could change the narrative since EVs work majorly on a regenerative braking system implying that the vehicle friction brakes are rarely in use. This could indicate that the maximum operating temperature that brake discs are commonly subjected to becomes lower, especially for hybrid and electric cars, in the future. This development might pave the way for aluminum matrix composite as a potential material for future brake disc development.

\section{Conclusions}

This paper discusses some trending in automobiles development that would drive the future automotive brake discs material requirements. The influence of PM emissions control, disc corrosion resistance, lightweight solution and brake noise control in determining the future of brake discs design and development are also highlighted.

\section{Acknowledgement}

None.

\section{Conflict of Interest}

There is no conflict of interest.

\section{References}

1. Reif K (2014) Brakes, Brake Control and Driver Assistance Systems: Function, Regulation and Components. Springer Vieweg.

2. Rashid A (2014) Overview of disc brakes and related phenomena - a review. Int J Veh Noise Vib 10(4): 257.

3. Kahl, M (2016) Special report: Vehicle lightweighting. Automotive World.
4. Van der Gon HA, Gerlofs-Nijland ME, Gehrig R, Gustafsson M, Janssen $\mathrm{N}$, et al. (2013) The policy relevance of wear emissions from road transport, now and in the future - An International Workshop Report and Consensus Statement. J Air Waste Manag Assoc 63(2): 136-149.

5. Denier van der Gon H, Hulskotte J, Jozwicka M, et al. (2018) European Emission Inventories and Projections for Road Transport Non-Exhaust Emissions: Analysis of Consistency and Gaps in Emission Inventories From EU Member States. In: Non-Exhaust Emissions. Elsevier, pp. 101121.

6. Amato F, Cassee FR, Denier van der Gon HA, Gehrig R, Gustafsson M, et al. (2014) Urban air quality: The challenge of traffic non-exhaust emissions. J Hazard Mater 275: 31-36.

7. Wahid SMS (2018) Automotive brake wear: a review. Environ Sci Pollut Res 25(1): 174-180.

8. Victor RJH Timmers, Peter AJ Achten (2018) Non-Exhaust PM Emissions From Battery Electric Vehicles. In: Non-Exhaust Emissions. Elsevier, pp. 261-287.

9. Aranke O, Algenaid W, Awe S, Joshi S (2019) Coatings for Automotive Gray Cast Iron Brake Discs: A Review. Coatings 9(9): 552.

10. Wakeling D, Murrells T, Carslaw D, John Norris, Luke Jones (2017) The Contribution of Brake Wear Emissions to Particulate Matter in Ambient Air. Project report for the German Research Association of Automotive Technology (FAT)

11. Maleque MA, Dyuti S, Rahman MM (2010) Material Selection Method in Design of Automotive Brake Disc. Proc World Congr Eng 3: 1-5.

12. Kevorkijan V (2003) Engineering wear-resistant surfaces in automotive aluminium. Jom 55(2): 32-34.

13. Malcolm K Stanford, Vinod KJain (2001) Friction and wear characteristics of hard coatings. Wear 250(1-2): 990-996.

14. Shin MW, Cho KH, Kim SJ, Jang H (2010) Friction instability induced by corrosion of grey iron brake discs. Tribol Lett 37(2): 149-157.

15. Ghazaly NM, El-Sharkawy M, Ahmed I (2014) A Review of Automotive Brake Squeal Mechanisms. J Mech Des Vib 1: 5-9. 